\title{
Ultrasonic study of molecular interaction in ternary liquid mixtures at $293 \mathrm{~K}$
}

\author{
Shubhajit Halder, Pratibha. S. Agrawal, ${ }^{* *}$ Shivani Thakur, ${ }^{*}$ and \\ Lalitmohan. J. Paliwal. \\ "Dr. Mrs. Ira N.Nimdeokar P.G. and Research centre for Chemistry, Hislop College, Nagpur-440001(M.S), \\ India \\ ${ }^{* *}$ Department of Applied Chemistry, Laxminarayan Institute of Technology , RTM Nagpur University, Nagpur- \\ 440033 (M.S), India \\ ${ }^{* * *}$ Department of Chemistry, RTM Nagpur University, Nagpur-440033 (M.S), India
}

\begin{abstract}
Densities and ultrasonic speeds of the ternary liquid mixture of diethyl amine with acetone and acetophenone in $n$-hexane at $293 \mathrm{~K}$ over the entire composition range were measured. From these data, acoustical parameters such as adiabatic compressibility $(\beta)$, intermolecular free length $\left(L_{f}\right)$, acoustic impedance $(Z)$, internal pressure $\left(\pi_{i}\right)$, excess velocity $\left(U^{E}\right)$, excess adiabatic compressibility $\left(\beta^{E}\right)$, excess intermolecular free length $\left(L_{f}^{E}\right)$, excess acoustic impedance $\left(Z^{E}\right)$ have been evaluated. These excess parameters have been used to discuss the nature and extent of interaction between the component molecules in the ternary mixtures. The ultrasonic speeds calculated according to Nomoto's relation, Rao's specific sound velocity theory and impedance dependence relation and are compared with those obtained experimentally.
\end{abstract}

Keywords: Ultrasonic speeds, Acoustic impedance, Intermolecular free length, Excess adiabatic compressibility.

\section{Introduction}

Measurements of ultrasonic investigations find extensive applications in predicting the physicochemical behaviour of liquid mixtures [1-4]. Ultrasonic velocity in a liquid mixture is fundamentally related with the binding forces acting between the atoms or molecules present in the liquid systems [5].

These studies can also be used to identify complexation and to calculate the stability constants of complexes [7-8]. The donor-acceptor complex formation is biologically important. Oxygen transfer in blood involves reversible complexation between haeme and oxygen. Electron-deficient carbons of carbonyl group can act as electrophiles. Basic groups like amino groups can interact with this group to form a complex and influence the properties of such compound [9]. In this paper, the results obtained in the study of molecular interaction between diethyl amine with acetone and acetophenone in $n$-hexane solvent have been reported over the entire composition at $293 \mathrm{~K}$. Molecular interactions among the components of the mixtures were inferred from the sign of the excess and deviation properties.

\section{Experimental}

Diethyl amine, Acetone and Acetophenone were Anal R grade. The solvent $\mathrm{n}$-hexane was purified by distillation (b.p. $69^{\circ} \mathrm{C}$ ) before use. Densities, Viscosities and Ultrasonic Velocities were measured at 293K over a wide range of concentrations $(0.02-0.2 \mathrm{M})$. The densities of pure compounds and their solutions were measured accurately using Rudolph digital densitometer (accuracy \pm 0.1 ). Viscosities of pure compounds and their mixtures were determined using Ostwald's Viscometer calibrated with double distilled water.

The ultrasonic velocity was measured by using variable path single crystal interferometer (Model F81S, Mittal Enterprise, India) at fixed frequency $2 \mathrm{MHz}$ with accuracy of $\pm 0.1 \mathrm{~ms}^{-1}$. The temperature of the solution under study is maintained constant using the electronic Juloba thermostat. This thermostat is equipped with a heater, a stirrer, a thermometer and a regulator. The temperature was maintained with an accuracy of $\pm 0.1 \mathrm{~K}$. Acoustical parameters such as adiabatic compressibility $(\beta)$, free length $\left(\mathrm{L}_{\mathrm{f}}\right)$, acoustic impedance $(\mathrm{Z})$ internal pressure $\left(\pi_{\mathrm{i}}\right)$, and relaxation time $(\tau)$ were calculated using standard equations [10].

$$
\begin{aligned}
& \beta=1 / \mathrm{U}^{2} \rho \\
& \mathrm{L}_{\mathrm{f}}=\mathrm{k} / \sqrt{\mathrm{U} \rho} \mathrm{A}^{0}
\end{aligned}
$$

where, $\mathrm{k}$ is Jacobson's constant. This constant is a temperature dependent parameter whose value at any temperature $(\mathrm{T})$ is given by $(93.875+0.345 \mathrm{~T}) \times 10^{-8}$.

$$
\begin{aligned}
& \mathrm{Z}=\rho \mathrm{U} \\
& \pi_{\mathrm{i}}=\mathrm{bRT}(\mathrm{K \eta} / \mathrm{U})^{1 / 2}\left(\rho^{2 / 3} / \mathrm{M}_{\mathrm{eff}}{ }^{7 / 6}\right)
\end{aligned}
$$


Where $\mathrm{b}$ is the cubic packing factor which is assumed to be 2 for all solutions, $\mathrm{K}$ is the temperature dependent constant whose value is $4.28 \times 10^{9}$, $\mathrm{R}$ is the universal gas constant, $\mathrm{T}$ is the absolute temperature.

$\mathrm{M}_{\text {eff }}$ is the effective molecular weight which is expressed as

$$
\mathrm{M}_{\mathrm{eff}}=\left(\mathrm{X}_{1} \mathrm{M}_{1}+\mathrm{X}_{2} \mathrm{M}_{2}+\mathrm{X}_{3} \mathrm{M}_{3}\right)
$$

Where $\mathrm{X}$ and $\mathrm{M}$ are the mole fraction and molar weight of the individual constituent in the mixture respectively.

$$
\tau=4 \eta / 3 \rho \mathrm{U}^{2}
$$

The strength of interaction between the component molecules of ternary mixtures is well reflected in the deviation of the excess functions from ideality [11]. The excess properties such as $U^{\mathrm{E}}, \beta^{\mathrm{E}}, \mathrm{L}_{\mathrm{f}}^{\mathrm{E}}$ and $\mathrm{Z}^{\mathrm{E}}$ were calculated using the equation

$$
\mathrm{Y}^{\mathrm{E}}=\mathrm{Y}_{\text {mix }}-\left[\mathrm{X}_{1} \mathrm{Y}_{1}+\mathrm{X}_{2} \mathrm{Y}_{2}+\mathrm{X}_{3} \mathrm{Y}_{3}\right]
$$

where $\mathrm{Y}^{\mathrm{E}}$ is $\mathrm{U}^{\mathrm{E}}$ or $\beta^{\mathrm{E}}$ or $\mathrm{L}_{\mathrm{f}}^{\mathrm{E}}$ or $\mathrm{Z}^{\mathrm{E}}$ and $\mathrm{X}$ represents mole fractions of the component and subscript 1,2 and 3 for the components 1,2 and 3 .

The different theoretical ultrasonic velocity relations used in the present study are expressed as follows, Nomoto's relation [12].

$\mathrm{U}_{\mathrm{NR}}=\left[\left(\mathrm{X}_{1} \mathrm{R}_{1}+\mathrm{X}_{2} \mathrm{R}_{2}+\mathrm{X}_{3} \mathrm{R}_{3}\right) /\left(\mathrm{X}_{1} \mathrm{~V}_{1}+\mathrm{X}_{2} \mathrm{~V}_{2}+\mathrm{X}_{3} \mathrm{~V}_{3}\right)\right]^{3}$

where $X_{1}, X_{2}, X_{3}$, are the mole fraction of the liquid mixtures. $R_{1}, R_{2}, R_{3}$ the molar sound velocity and

$\mathrm{V}_{1}, \mathrm{~V}_{2}, \mathrm{~V}_{3}$ are the molar volume of the components of ternary mixture.

Rao's specific sound velocity relation [13]

$\mathrm{U}_{\mathrm{R}}=\left(\sum \mathrm{x}_{\mathrm{i}} \mathrm{r}_{\mathrm{i}} \rho\right)^{3}$

where $x_{i}$ is the mole fraction, $r_{i}$ is the Rao's specific sound velocity $=u_{i}{ }^{1 / 3} / \rho_{i}, \rho$ is the density of the mixture, $\rho_{i}$ is the density and $u_{i}$ is the velocity of the $i^{\text {th }}$ component of the mixture.

Impedance dependent relation [14]

$\mathrm{U}=\left(\sum \mathrm{X}_{\mathrm{i}} \mathrm{Z}_{\mathrm{i}}\right) /\left(\sum \mathrm{X}_{\mathrm{i}} \rho_{\mathrm{i}}\right)$

where $X_{i}$, is the mole fraction, $Z_{i}$ is the acoustic impedance and $\rho_{i}$ is the density of the $i^{\text {th }}$ component of the mixture.

\section{Results and Discussion}

The experimental densities and ultrasonic velocities at $293 \mathrm{~K}$ of the pure liquids are presented in Table 1. The calculated values for various acoustical parameters such as $\beta, L_{f}, Z$ and $\pi_{\mathrm{i}}$ are given in Table 2. Adiabatic compressibility $(\beta)$ is a measure of intermolecular association or dissociation or repulsion. It also determines the orientation of the solvent molecules around the liquid molecule. The structural arrangement of the molecule affects the adiabatic compressibility. It is found that the adiabatic compressibility decreases with increasing concentration for both the system. This trend suggests that there is significant interaction between unlike molecules [15].

The free length is the distance between the surfaces of the neighbouring molecules. Generally, when the ultrasonic velocity increases, the value of the free length decreases [16]. The decrease in intermolecular free length indicates the interaction between the solute and solvent molecules due to which the structural arrangement in the neighbourhood of constituent ions or molecules gets affected considerably.

Sounds travels through materials under the influence of sound pressure. Since, molecules or atoms of a liquid are bound elastically to one another, the excess pressure results in a wave propagating through the liquid. Increasing trend of $\mathrm{Z}$ for both the systems is in agreement of increasing ultrasonic speed of the solutions.

The internal pressure is a measure of cohesive forces between the component molecules. The value of $\pi_{\mathrm{i}}$ increases for diethyl amine-acetone-n-hexane system due to the various degrees of dispersive interaction and the columbic interaction existing between the component molecules.

In order to highlight the presence of interaction between the molecules, it is essential to study the excess parameters. The deviation of a physical property of the liquid mixtures from the ideal behaviour is a measure of the interaction between the molecules, which may be due to either adhesive or cohesive force.

Table 1 Experimental values of the Ultrasonic velocity and density of pure liquids.

\begin{tabular}{lll}
\hline Liquid & $\begin{array}{l}\text { Ultrasonic Velocity }(\mathrm{U}) \\
\mathrm{m} \cdot \mathrm{s}^{-1}\end{array}$ & Density $(\rho) \mathrm{kg} \cdot \mathrm{m}^{-3}$ \\
\hline Acetone & 1185 & 790 \\
Acetophenone & 1468.8 & 1028 \\
Diethyl amine & 2081 & 707.4 \\
Hexane & 1099.8 & 658 \\
\hline
\end{tabular}


Table 2 Values of $U, \rho, \beta, L_{f}, Z$ and $\pi_{i}$ of ternary system as a function of equimolar concentration of amine and ketone at $293 \mathrm{~K}$.

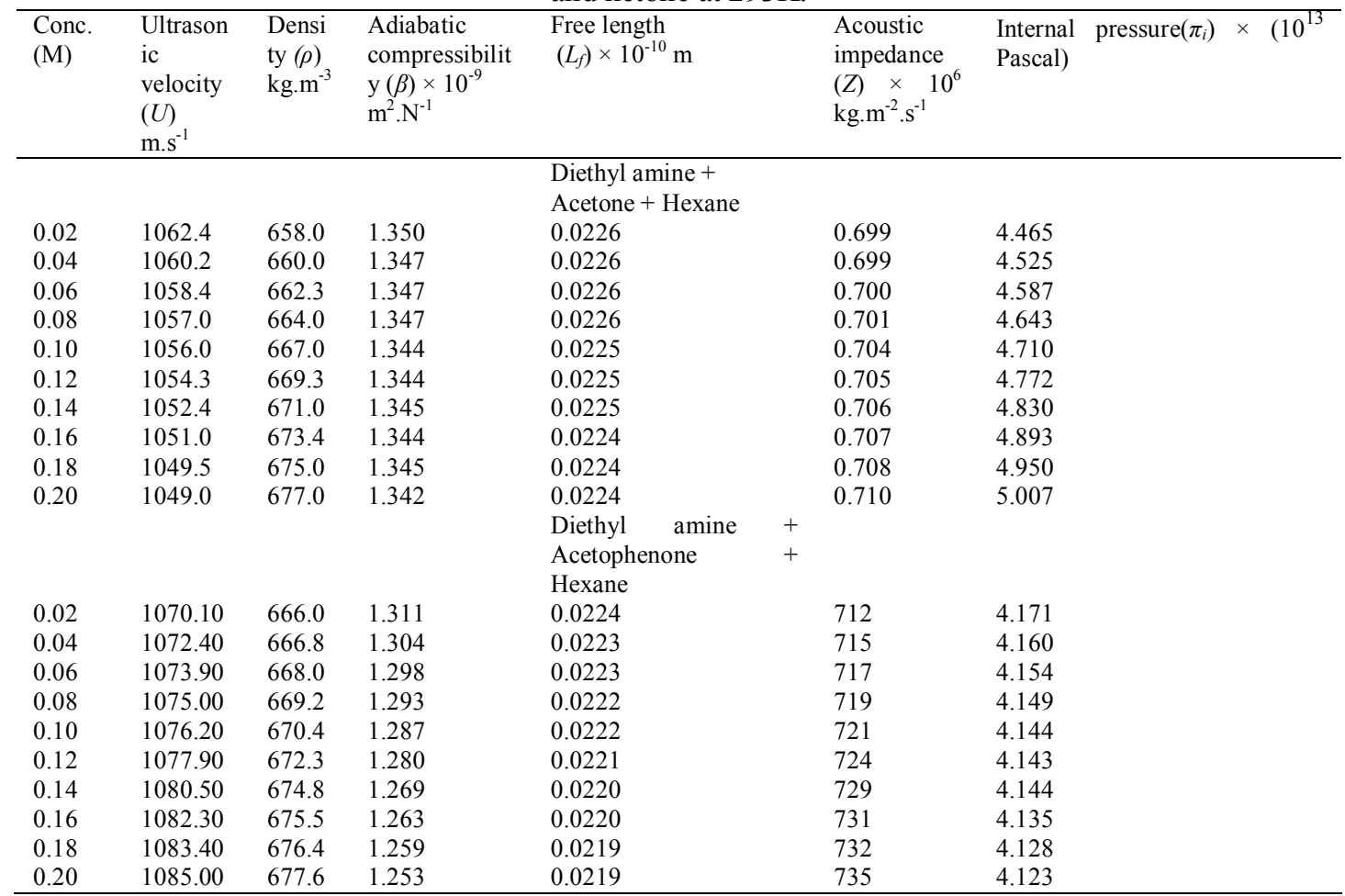

Table 3 Excess values of ultrasonic velocity $\left(U^{E}\right)$, adiabatic compressibility $\left(\beta^{E}\right)$, intermolecular free length

\begin{tabular}{|c|c|c|c|c|}
\hline Conc.(M) & $\begin{array}{l}\text { Excess } \\
\text { ultrasonic } \\
\text { velocity }\left(U^{E}\right) \\
\mathrm{m} . \mathrm{s}^{-1}\end{array}$ & $\begin{array}{l}\text { Excess adiabatic } \\
\text { compressibility }\left(\beta^{E}\right) \\
\times 10^{-9} \\
\mathrm{~m}^{2} \cdot \mathrm{N}^{-1}\end{array}$ & $\begin{array}{l}\text { Excess intermolecular free } \\
\text { length }\left(L_{f}^{E}\right) \times 10^{-10} \mathrm{~m}\end{array}$ & $\begin{array}{l}\text { Excess acoustic impedance }\left(Z^{E}\right) \times \\
10^{6} \mathrm{~kg} \cdot \mathrm{m}^{-2} \cdot \mathrm{s}^{-1}\end{array}$ \\
\hline \multicolumn{5}{|c|}{ Diethyl amine + Acetone $+n$ Hexane } \\
\hline 0.02 & -51.2025 & -0.00054 & 0.0010 & -37737.647 \\
\hline 0.04 & -66.9215 & -0.00054 & 0.0012 & -49923.713 \\
\hline 0.06 & -81.9658 & -0.00053 & 0.0014 & -61274.897 \\
\hline 0.08 & -96.3436 & -0.00053 & 0.0015 & -72749.247 \\
\hline 0.10 & -110.0629 & -0.00052 & 0.0017 & -82343.378 \\
\hline 0.12 & -124.2313 & -0.00052 & 0.0019 & -92911.895 \\
\hline 0.14 & -138.3562 & -0.00051 & 0.0020 & -104022.36 \\
\hline 0.16 & -151.7446 & -0.00051 & 0.0022 & -113842.32 \\
\hline 0.18 & -165.0033 & -0.00051 & 0.0024 & -124357.73 \\
\hline 0.20 & -177.0389 & -0.00050 & 0.0025 & -133569.51 \\
\hline \multicolumn{5}{|c|}{ Diethyl amine + Acetophenone $+\mathrm{n}$ Hexane } \\
\hline 0.02 & -46.2004 & 0.0755 & 0.0007 & -29202.76 \\
\hline 0.04 & -60.2740 & 0.0888 & 0.0009 & -44893.928 \\
\hline 0.06 & -75.0222 & 0.1033 & 0.0011 & -60547.473 \\
\hline 0.08 & -90.0465 & 0.1185 & 0.0012 & -76328.22 \\
\hline 0.10 & -104.8482 & 0.1335 & 0.0014 & -91903.969 \\
\hline 0.12 & -119.0288 & 0.1457 & 0.0016 & -106252.73 \\
\hline 0.14 & -132.1895 & 0.1546 & 0.0017 & -119207.68 \\
\hline 0.16 & -146.0319 & 0.1688 & 0.0019 & -134508.83 \\
\hline 0.18 & -160.4572 & 0.1840 & 0.0021 & -149934.81 \\
\hline 0.20 & -174.2666 & 0.1974 & 0.0022 & -164566.81 \\
\hline
\end{tabular}

Table 3 presents that the value of $\mathrm{U}^{\mathrm{E}}$ is negative which indicate the presence of weak interaction between the component molecules[17]. This supports our view that the interactions between the two ternary mixtures are weaker. The excess positive $\beta^{\mathrm{E}}$ values for diethyl amine + acetophenone $+\mathrm{n}-\mathrm{Hexane}$ system represent the dispersion forces while the negative values for diethyl amine + acetone $+n-H e x a n e$ interprets the charge transfer interaction between the unlike molecules [18].

The values of $\mathrm{L}_{\mathrm{f}}^{\mathrm{E}}$ are positive which indicates weak molecular interaction between the components of the mixtures, which results from dispersion force. The negative $Z^{\mathrm{E}}$ values in both ternary mixtures indicate the weakening of intermolecular interactions between the component molecules. 
Table 4 Theoretical ultrasonic velocities calculated using Nomoto's relation, Rao's specific sound and Impedance dependence relation velocity theory along with experimental values and the percentage error for two ternary systems at $293 \mathrm{~K}$

\begin{tabular}{|c|c|c|c|c|c|c|c|}
\hline \multirow[t]{2}{*}{ Concentration } & \multirow[t]{2}{*}{ Expt. } & \multicolumn{3}{|c|}{ Ultrasonic Velocity, $\mathrm{U}, \mathrm{ms}^{-1}$} & \multicolumn{3}{|c|}{$\%$ Deviation } \\
\hline & & Nomoto & Rao & Impedance & Nomoto & Rao & Impedance \\
\hline & & & \multicolumn{5}{|c|}{ Diethyl amine + Acetone + n-Hexane } \\
\hline 0.02 & 1062.4 & 1035.8 & 1023.2 & 1114.8 & 2.5003 & 3.6905 & -4.9285 \\
\hline 0.04 & 1060.2 & 1046.1 & 1030.4 & 1129.3 & 1.3289 & 2.8151 & -6.5162 \\
\hline 0.06 & 1058.4 & 1056.2 & 1039.0 & 1143.4 & 0.2039 & 1.8337 & -8.0302 \\
\hline 0.08 & 1057.0 & 1066.2 & 1044.9 & 1157.1 & -0.8735 & 1.1473 & -9.4702 \\
\hline 0.1 & 1056.0 & 1076.1 & 1057.0 & 1170.4 & -1.902 & -0.0923 & -10.8357 \\
\hline 0.12 & 1054.3 & 1085.8 & 1065.8 & 1183.4 & -2.9879 & -1.0952 & -12.2435 \\
\hline 0.14 & 1052.4 & 1095.4 & 1071.9 & 1196.0 & -4.0845 & -1.8544 & -13.644 \\
\hline 0.16 & 1051.0 & 1104.8 & 1081.4 & 1208.3 & -5.1226 & -2.8931 & -14.9626 \\
\hline 0.18 & 1049.5 & 1114.2 & 1087.1 & 1220.2 & -6.1613 & -3.5835 & -16.265 \\
\hline \multirow[t]{2}{*}{0.20} & 1049.0 & 1123.4 & 1094.8 & 1231.8 & -7.0888 & -4.3660 & -17.4293 \\
\hline & \multicolumn{7}{|c|}{ Diethyl amine + Acetophenone + n-Hexane } \\
\hline 0.02 & 1070.1 & 1038.0 & 1058.7 & 1119.4 & 2.9996 & 1.0646 & -4.6075 \\
\hline 0.04 & 1072.4 & 1050.6 & 1058.0 & 1138.6 & 2.0338 & 1.3435 & -6.1714 \\
\hline 0.06 & 1073.9 & 1063.2 & 1059.2 & 1157.3 & 0.9981 & 1.3686 & -7.7705 \\
\hline 0.08 & 1075.0 & 1075.8 & 1060.4 & 1175.7 & -0.0722 & 1.3552 & -9.3686 \\
\hline 0.1 & 1076.2 & 1088.4 & 1061.7 & 1193.7 & -1.1312 & 1.3492 & -10.9171 \\
\hline 0.12 & 1077.9 & 1101.0 & 1066.3 & 1211.3 & -2.1405 & 1.0786 & -12.3753 \\
\hline 0.14 & 1080.5 & 1113.6 & 1073.8 & 1228.5 & -3.0608 & 0.6246 & -13.7004 \\
\hline 0.16 & 1082.3 & 1126.2 & 1072.7 & 1245.4 & -4.0535 & 0.8901 & -15.0716 \\
\hline 0.18 & 1083.4 & 1138.8 & 1072.6 & 1262.0 & -5.1108 & 1.0007 & -16.4820 \\
\hline 0.20 & 1085.0 & 1151.4 & 1073.9 & 1278.2 & -6.1168 & 1.0234 & -17.8046 \\
\hline
\end{tabular}

Theoretical evaluation of ultrasonic speeds in liquid mixtures offers a simple and convenient method [19] for the study of the nature of molecular interactions in these mixtures. The theoretical values of ultrasonic speeds, evaluated using Nomoto's relation, impedance dependence relation and Rao's specific sound velocity theory along with the experimental values and percentage deviation in the calculated values are presented in Table 4 for comparisons. On comparison, the results indicate that for both the systems, diethyl amine + acetone $+n$-Hexane mixtures, minimum deviations are observed in case of Rao's specific sound velocity theory followed by Nomoto's relation and impedance dependence relation shows the maximum deviation.

\section{Conclusion}

The results of the present study indicate that the thermodynamic parameters are sensitive to the molecular interactions present in the liquid mixtures. The positive values of $\mathrm{L}_{\mathrm{f}}^{\mathrm{E}}$ and the negative values of $\mathrm{U}^{\mathrm{E}}, \mathrm{Z}$ $\mathrm{E}$ indicates the presence of weak dipolar and dispersive interactions between the component molecules over the entire composition range of both ternary mixtures. The charge transfer interaction between diethyl amine and acetone is clearly revealed by negative $\beta^{\mathrm{E}}$ values for diethyl amine + acetone $+\mathrm{n}$-Hexane system. The theoretical values of ultrasonic velocities are calculated by using Nomoto's relation, Rao's specific sound velocity theory and impedance dependence relation. Among the three theories taken up for the prediction of sound velocity, a good agreement in experimental and theoretical values of velocity is observed in case of Rao's specific sound velocity theory for both ternary systems.

\section{Acknowledgements}

One of the authors (SH) is thankful to the Director of Dr. Mrs. Ira N.Nimdeokar P.G. and Research centre for Chemistry, Hislop College, Nagpur for providing laboratory facilities.

\section{References}

[1]. J.R. Sekar, P.R. Naidu and W.E. Acree Jr, J.Chem.Eng.Data., 38 ,167 (1993)

[2]. T. Takagi and H. Teranishi, J.Chem Thermodyn, 14, 1167(1982).

[3]. D.J. Pandey, R. Dey and K.D. Dwivedi, Pramana J Phys.52,187(1999)

[4]. S. Azhagiri, S. Jayakumar, R. Padmanaban and S. S. Srinivasan, J Solution Chem.38, 441 (2009). 
[5]. A. Pal, R. Gaba and H. Kumar, J Solution Chem., 40, 786 (2011).

[6]. J. Nath and R. Paikray, Indian J.Phys., 83, 1309(2009).

[7]. V. Kannappan and N. I. Gandhi, Phys chem liq., 40, 507 (2002)

[8]. V. Kannappan, J.R. Santhi and P.J.E. Malar, Phys chem liq., 40, 507 (2002).

[9]. Organic Chemistry,W.T. Graham Solomons and B.C. Fryhle, 2002, John Wiley \& Sons, Inc. New York,p.1176 (2002)

[10]. S. Prabhakar and K. Rajagopal, J. Pure Appl.Ultrason.,27,41 (2005)

[11]. Y. Maham, N.C. Liew and E.A.Mather, J Solution Chem., 40, 743(2002)

[12]. O. Nomoto, J.Phys.Soc.Jpn., 13, 1528(1958).

[13]. R.M. Rao and J.Chem.Phys., 9, 682 (1941).

[14]. M. Kalidoss and R. Srinivasamoorthy, J. Pure Appl.Ultrason., 19, 9 (1997).

[15]. A. Ali and A.K.Nain, J. Pure Appl.Ultrason., 21,31 (1999).

[16]. J.F. Kincaid and H Eyring, J. Chem. Phys., 6, 620 (1938)

[17]. A.A. Yasmin and A.K. Nain, Indian J Pure \& Appl Phys., 40,315 (2002).

[18]. J.R Fort and R.W. Moore, Trans. Faraday Soc., 62, 1112 (1966).

[19]. A Ali and A.K. Nain, Bull Chem. Soc Japan.,75, 681 (2002). 